\title{
A SUA REVISTA TEM QUALIS? ${ }^{1}$
}

\section{Antonio Ozaí da Silva}

\begin{abstract}
Resumo
Neste artigo o autor examina criticamente o sistema de avaliação Qualis. 0 que está em jogo? Será mesmo possível avaliar a qualidade do que é publicado no campo acadêmico? Ou trata-se apenas de um meio de controle? Observa que pressionados pela exigência de mais e mais produtividade, os docentes perdem o senso crítico, reproduzem o servilismo e mutilam-se para atender às normas e regras burocráticas decididas por um grupo seleto de indivíduos.
\end{abstract}

Palavras-chave: Qualis. Avaliação. Academia.

\section{Does Your Journal have Qualis? \\ Abstract}

In this article the author critically examines the Qualis evaluation system. What is at stake? Is it really possible to evaluate the quality of what is published in the academic field? Or is it simply a means of control? It appears that, pressured by the need to be more and more productive, faculty lose their critical sense, reproduce subservience and mutilate themselves to accomodate the bureaucratic norms and rules determined by a select group of individuals.

Keywords: Qualis. Evaluation. Academe.

\footnotetext{
${ }^{1}$ Versão ampliada e modificada do texto publicado na Revista Espaço Acadêmico, no 56 , janeiro de 2006, disponível em http://www.espacoacademico.com.br/056/560zai.htm

${ }^{2}$ Professor na Universidade Estadual de Maringá (DCS/UEM), editor da Revista Espaço Acadêmico, Revista Urutágua e Acta Scientiarum. Human and Social Sciences e autor de Maurício Tragtenberg: Militância e Pedagogia Libertária (Ijuí: Editora Unijuí, 2008). Blog: http://antoniozai.blogspot.com Email: aosilva@uem.br
} 
$\mathrm{A}$ primeira vez que me fizeram esta pergunta, a minha reação foi de perplexidade (e, ironicamente, me veio à mente o nome de uma marca de margarina). Respondi de maneira educada e sincera ao meu inquiridor: desconhecia o "Qualis". Admito, no entanto, que este tipo de pergunta me causava certa irritabilidade, imediatamente controlada através do exercício da tolerância acadêmica. Mas como ficar insensível diante dos modismos, mecanismos de controle e das manias classificatórias criadas pela "comunidade acadêmica", as quais se fundamentam em critérios quantitativos pretensamente objetivos? Como não se irritar quando percebemos que, muitas vezes, preocupam-se mais com os meios do que com os fins?

Penso que o verdadeiro "Qualis", que atesta ou não a qualidade de uma revista acadêmica é o que proporciona a sua existência. 0 que a qualifica - ou não - é o trabalho do seu corpo editorial, do conselho de consultores, os autores que submetem seus textos à apreciação e, especialmente, seus leitores. Afinal, é para estes que a revista existe. Longe de mim desmerecer o abnegado trabalho dos doutos que compõem a "autoridade científica", as "comissões" disso e daquilo que definem e aplicam os critérios classificatórios. Afirmo apenas o óbvio: o que dá vida a um periódico é o grupo que o compõe e os resultados que alcança ao angariar o apoio, a colaboração e o respeito dos seus leitores. A propósito, como são compostas essas comissões? Sabemos quem nos representam nessas estruturas? São mesmo representativas dos seus pares? Foram indicadas por procedimentos democráticos?

Será que o "Qualis" é mesmo capaz de avaliar a qualidade do que é publicado no campo acadêmico? Ou será apenas um meio de controle a partir de definições de regras e procedimentos formais, aos quais todos se vêem obrigados a se enquadrar. Mas será que tais critérios são capazes de medir o alcance de um periódico? Podemos mensurar a influência e o significado real dos artigos das revistas sobre os seus leitores? A "comunidade acadêmica" objetiva traduzir em conceitos o que seria a "qualidade", o "Qualis", de cada revista. ${ }^{3}$ Será possível traduzir em números ou conceitos que expressem sua qualidade?

\footnotetext{
${ }^{3}$ Esta pretensão é relativizada: "No entanto, não se pretende, com essa classificação, que é específica para um processo de avaliação de área, definir qualidade de periódicos de forma absoluta". (http://qualis.capes.gov.br/, acesso em 02 de janeiro de 2006).
} 


\section{Efeitos do Qualis}

0 Qualis é parte do processo de avaliaçã̃o do Sistema Nacional de PósGraduação. Sua função, portanto, é contribuir para a avaliação das revistas disponíveis à divulgação da produção intelectual dos pesquisadores e docentes vinculados aos programas de pós-graduação. Os órgãos de publicação são, então, classificados segundo o âmbito de circulação e a qualidade, por área de avaliação. Os critérios são definidos por ilustres senhores e senhoras que compõem as comissões de consultores e, em tese, representam a comunidade científica. Cada área estabelece os critérios classificatórios.

Aparentemente, tudo é muito simples: pessoas idôneas, qualificadas e bemintencionadas definem os critérios para avaliação e classificação dos periódicos. A partir dessa definição, estes são anualmente classificados segundo a sua "qualidade". Mas como se chega a essa "qualidade"? Será que todos temos as mesmas condições de trabalho para atender os critérios exigidos para ganharmos 0 "selo de qualidade" ambicionado?

Na prática, estabelece-se uma hierarquia de publicações e passa-se uma mensagem explícita aos autores: publiquem na revista "X" e não na " $Y$ ", porque a primeira tem conceito Qualis mais elevado. Pressupõe-se que os critérios são objetivos, isto é, que a informalidade, as relações pessoais, os interesses individuais e de grupos, afora as idiossincrasias dos editores ou corpos editoriais e dos consultores não têm qualquer influência. Será?!

Para além do discurso da busca da qualidade, o qual parece sensato, o fato é que essa política classificatória, hierarquizante e potencialmente indutiva, influencia o fluxo das publicações e, conseqüentemente, o cotidiano dos docentes e suas expectativas, bem como as dos programas de pós-graduação. Isso se estende às agências de fomento e aos processos de avaliação dos professores pelas instituiç̧̃es de ensino. Quanto melhor situado na hierarquia do Qualis, maior o poder de atração e mais as chances de influenciar na captação de financiamentos.

Os próprios autores tendem a hierarquizar suas "produções intelectuais". Certa vez, um colega argumentou, com toda sinceridade, que enviou seu artigo à revista "X" porque este era um "trabalho" sem maiores pretensões - e claro, este periódico, na sua forma de ver, estava "qualificado" para publicá-lo; para a revista " $\mathrm{Y}$ ", mais conceituada segundo o Qualis, enviaria outro texto, presumivelmente mais "qualificado". Portanto, à pergunta "Sua revista ter Qualis?", a resposta de um simples "SIM" não é suficiente. É preciso saber qual o conceito Qualis. 
À exigência de publicar soma-se a necessidade de identificar "onde publicar". 0 Qualis passa a ser, então, um poderoso indicador sobre quais periódicos valem a pena - ou não - publicar. Isso se você quiser atingir o topo. 0 objetivo de publicizar, tornar público, é condicionado pelo tipo de veículo. Em tese a qualidade do que é produzido é garantido pela qualidade do periódico que veicula. Isso produz um círculo vicioso com a tendência para que estes veículos se tornem cada vez mais restritivos. Muitos não serão admitidos no Olimpo, mas são pressionados, pela própria situação a procurar, o melhor Qualis. Claro, como em tudo na vida, há exceções.

\section{Fundamentos do Qualis}

0 Qualis é pensado como uma espécie de "qualimômetro", ou seja, um medidor da qualidade dos periódicos e, por conseguinte, do que é publicado. De fato, funda-se 1) na necessidade de produção, na exigência de produtividade cada vez maior; e, 2) no poder burocrático (as instituições que detêm o controle dos recursos necessários à pesquisa e à produção intelectual e o poder de decidir normas que influenciam decisivamente sobre a carreira docente), um poder acima e alienado da massa de docentes e pesquisadores, os quais não têm controle sobre os mesmos mas se vêem obrigados a se submeterem.

Trata-se de uma espécie de "servidão voluntária" que nos atinge como uma doença inoculada por determinações e procedimentos das instâncias "superiores". Por que, em geral, aceitamos os ditames das "autoridades científicas" e administrativas-burocráticas e, quase sempre, nos adaptamos e as aplaudimos sem questionar? Por que precisamos de um corpo especialmente instituído para nos conceder uma espécie de ISO 9000? Diante da corrida pelo Lattes (SILVA, 2005) ${ }^{4}$ que nos foi imposta por esta mesma "comunidade acadêmica", muitos preferem se adaptar e aceitar de maneira subserviente. Entre questionar os objetivos e a validade política - e mesmo científica - de tais procedimentos, preferem perguntar se a revista tem Qualis. Se tiver, ótimo! Se não, também não será desconsiderada enquanto possibilidade para publicar, pois, a despeito de tudo, é preciso "fazer o Lattes"!

A "comunidade acadêmica" não é uma abstração isenta de subjetividade, por mais que ainda existam os que acreditem em neutralidade axiológica.

${ }^{4}$ Uma versão ampliada deste trabalho foi publicada em Silva (2005a). 
São indivíduos de carne e osso, com ideologias e interesses particulares, em geral travestidos por uma racionalidade universalizante, como se o conceito "comunidade acadêmica" englobasse indiferentemente a todos os que compõem o "campo acadêmico". Isto, é claro, influencia a sua ação e as avaliações, embora se pretendam "objetivas". A "comunidade acadêmica" é expressão da disputa de interesses no "campo científico". ${ }^{5}$ Não é natural o fato de alguns pares serem alçados à posição de classificadores, os quais, no final das contas, determinam 0 reconhecimento e a qualidade da produção acadêmica: é o prestígio e 0 desprestígio que estão em jogo. Não é pouca coisa! Aliás, nem sempre é explícita a forma como estes são escolhidos para cumprirem tarefas nem sempre vinculadas aos interesses dos que compõem a maioria do "campo acadêmico". Trata-se, na essência, da disputa por ser ungido enquanto "autoridade científica", da conquista da legitimação dos seus pares. ${ }^{6}$

Diante do peso da "autoridade científica" é quase impossível não se curvar aos procedimentos, critérios e classificações. Ela, a "autoridade", faz o seu trabalho; façamos o nosso. E o faremos melhor se nossos objetivos extrapolarem os limites da adaptação e do conformismo, sem a "servidão voluntária" que apazigua as nossas consciências e nos torna objetos e meros expectadores alienados em nosso próprio "campo".

A imperiosa necessidade de publicar, isto é, de mais e mais produtividade, é um dos pilares do poder burocrático. 0 Qualis caminha pari passu com as exigências da produção intelectual. A carreira acadêmica e a sobrevivência dos programas de pós-graduação são determinados pela quantidade de artigos que os docentes publicam e pela capacidade deles em atender às exigências dos órgãos avaliadores. Tudo é quantificado, tudo é pontuado. Essa pressão, paradoxalmente, nega a pretensão do Qualis em ser o "qualimômetro". Na verdade, o que importa é publicar, ainda que hierarquize-se o que é publicado.

Este tipo de pressão favorece práticas nada condizentes com o que se espera

\footnotetext{
5 0 "campo científico", na definição de Bourdieu (1983, p. 122) é "sistema de relações objetivas entre posições adquiridas (em lutas anteriores), é o lugar, o espaço de jogo de uma luta concorrencial".

${ }^{6}$ A "autoridade científica" pode ser "definida, de maneira inseparável, como a capacidade técnica ou o poder social, ou, se quisermos, o monopólio da competência científica, compreendida como capacidade de falar e de agir legitimamente (isto é, de maneira autorizada e com autoridade), que é socialmente outorgada a um agente determinado" (BOURDIEU, 1983, p. 122-123).
} 
de um ponto de vista ético (SILVA, 2008)7. Como salienta Waters (2006, p.12), "há um elo causal entre a demanda corporativa pelo aumento da produtividade e o esvaziamento, em todas as publicações, de qualquer significação que não seja gerar números". A linha de montagem fordista-taylorista acadêmica produz coisas sem sentido, cujo principal objetivo é simplesmente atender à demanda por mais e mais "artigos", "livros", etc., dos organismos governamentais e privados que injetam dinheiro nas artérias da universidade. A ânsia por se agraciado pela oferta do "deus Estado" ou o "deus mercado", contribui para a cultura produtivista. Nestas circunstâncias, "o produto é tudo que conta, não sua recepção, não 0 uso humano. Isso é produção apenas com o valor de um fim em si mesmo e praticamente mais nenhum outro" (Id., p. 42).

A pressão é ainda maior quando se tem em vista as exigências dos órgãos superiores em relação à pós-graduação. Não é por acaso que nas ciências humanas adota-se uma prática muito comum em outras áreas, a qual consiste em aparecer como co-autor nos artigos dos orientandos. Muitas vezes, a co-autoria não se justifica e uma simples nota de agradecimento no rodapé faria justiça ao orientador, mas isso não conta ponto. Em nome da sobrevivência do programa e das necessidades docentes, entra-se no reino do vale tudo.

Em todas as áreas, a influência dos organismos superiores é determinante. Se você quer ter a mínima chance de ser agraciado com recursos, vencer um edital, etc., deve se submeter. E não basta ser submisso, tem que provar que está à altura do seu gesto, isto é, deve se enquadrar e corresponder às exigências de produtividade. 0 critério é mercadológico: ganha quem "produziu" mais, não importa a qualidade do que foi "produzido". A injeção de recursos públicos e privados acirra a pressão para que os concorrentes se "qualifiquem" para conquistá-los. Criam-se diferenciações internas, hierarquias mantidas por recursos externos. Os agraciados terão melhores condições para incorporar alunos a seus projetos e de influenciálos. Poderão manter a clientela e o fato de terem conquistado esta posição fortalece o status de vencedores. Não faltarão "mariposas" a rondar a luz que irradiam.

Pressionados pela exigência de mais e mais produtividade, os docentes reproduzem o servilismo na relação com os órgãos superiores. Mutilam-se para atender as normas e regras burocráticas decididas por um grupo seleto de indivíduos. A perda do senso crítico e submissão à ordem acadêmica talvez representem o efeito mais infausto e preocupante.

${ }^{7}$ Retomo, aqui, alguns argumentos. 


\section{Concluindo...}

Ao anuir com os critérios positivistas da medição matemática do saber, como se este pudesse ser verdadeiramente mensurado, numa clara rendição às áreas do conhecimento acadêmico que priorizam a quantificação e também aos princípios mercadológicos cada vez mais influentes no campus, acentua-se o "produtivismo". Na medida em que se prioriza a quantidade, compromete-se a qualidade do que é publicado.

Contudo, é imperativo manter o discurso da qualidade, o Qualis. Ele alimenta a apologia da competência (SILVA, 2002) e dissipa a realidade competitiva imposta pela quantificação, o produtivismo, a necessidade de status e a luta por recursos financeiros. Além do mais, cumpre bem o papel de legitimar a hierarquização e os pilares do poder burocrático. Não esqueçamos que toda essa estrutura só se mantém pela participação ativa dos que falam e agem em nome da maioria e pelo silêncio e/ou a "servidão voluntária" desta.

Claro, há resistências. Em geral, porém, limitadas ao poder burocrático. Parte-se do pressuposto de que as condições não são as mesmas para todos. Certo! Como exigir o mesmo se não partilhamos dos mesmos recursos e poder de decidir e fazer? Em várias instituições, gasta-se a maior parte do tempo para construir as condições necessárias para o trabalho docente e do pesquisador. A minoria das instituições, geralmente aquelas que constituem o establishment acadêmico, encontram-se em situação muito melhor. A pesquisa e a produção intelectual não se desenvolvem, portanto, em condições de igualdade. Quem está melhor situado tem não apenas as melhores condições, mas também maior influência e poder. Eis como se retroalimenta o círculo vicioso.

0 problema da crítica é que ela pretende mudar essa situação mantendo-se o status quo, isto é, reivindicando a "inclusão, maior participação, mais recurso e coisas do tipo. Na prática, isso significa ser aceito pelo establishment nas mesmas condições, ou seja, também ter assento no Olimpo. Ora, não há lugar para todos e essa estratégia pode até representar a conquista de "mais espaço" e "parcelas do poder", mas reproduz os mecanismos que sustentam o poder burocrático. Continua-se "nas estranhas da baleia". ${ }^{8}$

\footnotetext{
8 "As entranhas da baleia", escreve George Orwell, "são apenas um útero grande o suficiente para conter um adulto. Lá ficamos, no espaço almofadado e escuro em que nos encaixamos perfeitamente, com metros de gordura entre nós e a realidade, capazes de manter uma atitude da mais completa indiferença, não importa o que aconteça” (2005, p. 135).
} 


\section{REFERÊNCIAS}

BOURDIEU, Pierre. 0 Campo Científico. In: ORTIZ, Renato. Pierre Bourdieu: Sociologia. São Paulo: Ática, 1983, pp.122-55.

CAPES. Qualis - Classificação de Periódicos, Anais, Jornais e Revistas. Disponível em: http://qualis.capes.gov.br/ Acessado em 02.01.2006.

ORWELL, George. Dentro da baleia e outros ensaios. São Paulo: Companhia das Letras, 2005.

SILVA, Antonio Ozaí da. Somos todos delinqüentes acadêmicos. Revista Espaço Acadêmico, $\mathrm{n}^{0}$ 88, setembro de 2008. Disponível em http://www.espacoacademico. com.br/088/88ozai.htm.

. A corrida pelo Lattes. Revista Espaço Acadêmico, no 46, março de 2005. Disponível em http://www.espacoacademico.com.br/046/46ozai.htm.

. A corrida pelo Lattes. In: RAMPINELLI, Waldir; ALVIM, Valdir \& RODRIGUES, Gilmar (orgs.) Universidade: a democracia ameaçada. São Paulo: Xamã, 2005a, pp. 87-96.

Apologia da competência e defesa da universidade pública. Revista Espaço Acadêmico, no 14, julho de 2002. Disponível em http://www.espacoacademico. com.br/014/14pol.htm

WATERS, Lindsay. Inimigos da esperança: publicar, perecer e o eclipse da erudição. São Paulo: Editora da UNESP, 2006. 